\title{
Kinetic Energy Release in the Loss of Water from $n$-Propanol Cation
}

\author{
Joong Chul Choe \\ Department of Chemistry, University of Suwon, PO Box 77, Suwon 440-600, Korea. E-mail: jcchoe@suwon.ac.kr \\ Received January 13, 2005
}

Key Words : $n$-Propanol ion, Kinetic energy release, Metastable ion, Mass spectrometry

Unimolecular dissociations of ionized aliphatic alcohols have been investigated extensively. Interestingly, competition between loss of hydrogen atom and water is quite different for lower aliphatic alcohol cations with different chain lengths. Loss of $\mathrm{H}$ dominates in the dissociations of methanol and ethanol cations, while loss of $\mathrm{H}_{2} \mathrm{O}$ does in those of n-propanol and $n$-butanol cations. ${ }^{1-3}$ Theoretical studies $^{4-6}$ agree that a $\mathrm{H}$ atom of the methyl group migrates to the $\mathrm{O}$ atom of the hydroxyl group prior to loss of $\mathrm{H}_{2} \mathrm{O}$ from these alcohol ions. In a recent computational study, ${ }^{5}$ the energy barriers for the $\mathrm{H}$ migration in the $\mathrm{H}_{2} \mathrm{O}$ loss were compared. The barrier decreases as the aliphatic chain increases.

Very recently, we proposed a potential energy surface (PES) for the loss of $\mathrm{H}_{2} \mathrm{O}$ and $\mathrm{H}$ from $n$-propanol ion by density functional theory (DFT) molecular orbital calculations. ${ }^{6}$ Initially $\mathrm{CH}_{3} \mathrm{CH}_{2} \mathrm{CH}_{2} \mathrm{OH}^{+\bullet}$ isomerizes to ${ }^{\circ} \mathrm{CH}_{2} \mathrm{CH}_{2}$ $\mathrm{CH}_{2} \mathrm{OH}_{2}^{+}$via a five centered transition state $(1,4-\mathrm{H}$ shift $)$. This is the rat-determining step in the $\mathrm{H}_{2} \mathrm{O}$ loss. ${ }^{\circ} \mathrm{CH}_{2} \mathrm{CH}_{2}$ $\mathrm{CH}_{2} \mathrm{OH}_{2}{ }^{+}$undergoes further isomerizations to ion-dipole complexes, c- $\mathrm{C}_{3} \mathrm{H}_{6}{ }^{+} \cdot \bullet \cdot \mathrm{H}_{2} \mathrm{O}$ prior to loss of $\mathrm{H}_{2} \mathrm{O}$. Based on the obtained PES, the experimental results ${ }^{3}$ of the metastable dissociation such as the branching ratio and the isotopic effect on the $\mathrm{H}$ loss could be well interpreted by the statistical Rice-Ramsperger-Kassel-Marcus (RRKM) theory. ${ }^{7}$ The kinetic energy release (KER), however, has not been investigated in detail, which provides valuable information on the exit channel in dissociation. In this work, the KER distribution (KERD) in the $\mathrm{H}_{2} \mathrm{O}$ loss from metastable $n$ propanol cation has been investigated using mass-analyzed ion kinetic energy (MIKE) spectrometry. ${ }^{8}$ The nature of the dissociation is discussed by comparing the experimental result with statistical phase space theory (PST) calculations. ${ }^{9,10}$

\section{Experimental Section}

A double-focusing mass spectrometer with reverse geometry (VG ZAB-E) was used. $n$-Propanol was introduced to the ion source via a septum inlet and was ionized by $70 \mathrm{eV}$ electron ionization. Ion source temperature was maintained at $150{ }^{\circ} \mathrm{C}$ and ions generated were accelerated to $8 \mathrm{keV}$. MIKE spectrometry was used to observe the unimolecular dissociation of metastable $n$-propanol cation. The molecular ion was selected by the magnetic sector and the translational kinetic energy of a product ion generated in the second field- free region of the instrument was analyzed by the electric sector. To improve the quality of a MIKE spectrum, signal averaging was carried out for repetitive scans. $n$-Pronanol was the best grade commercially available and used without further purification

\section{Results and Discussion}

In the metastable dissociation of $n$-propanol ion, the $\mathrm{H}_{2} \mathrm{O}$ loss was dominant (>98\%) with a minor abundance of the $\mathrm{H}$
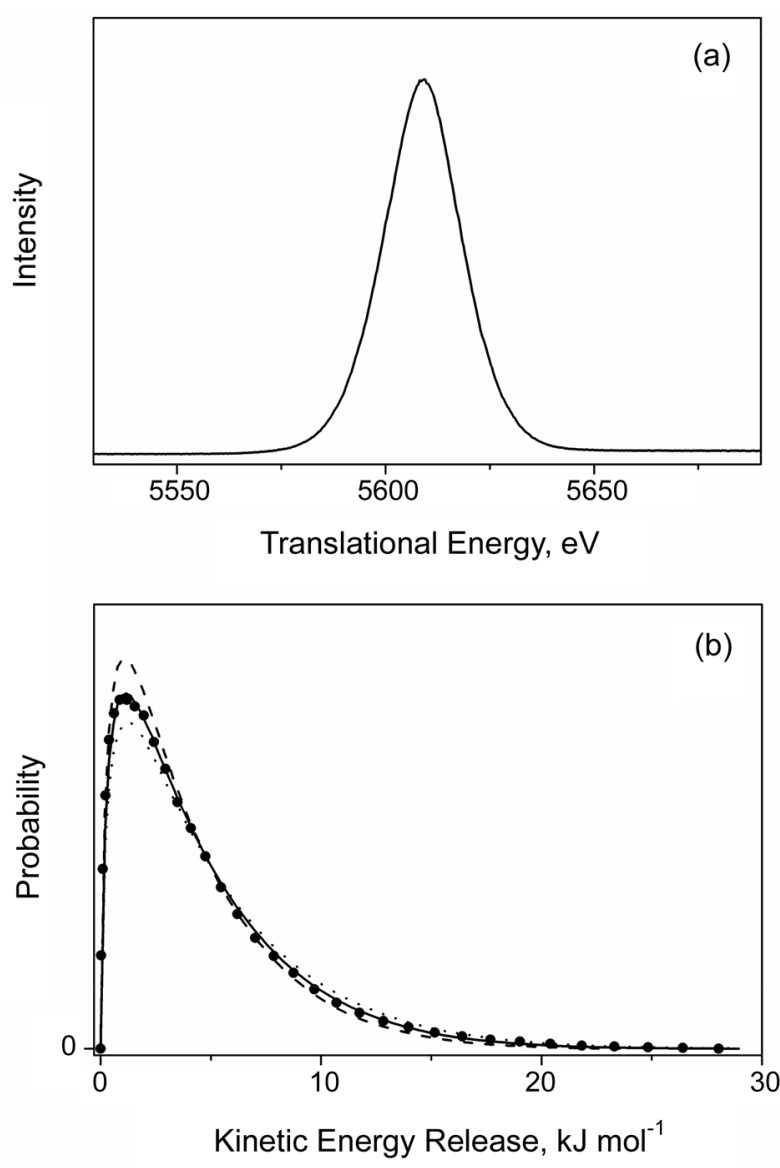

Figure 1. (a) The MIKE profile for the water loss from metastable $n$-propanol cation generated by electron ionization. (b) The KERDs for the water loss from metastable $n$-propanol cation. The experimental result evaluated for the profile in (a) is shown as points. The PST calculation results using the available energies of 29,24 , and $34 \mathrm{~kJ} \mathrm{~mol}^{-1}$ are shown as solid, dot, and dash curves, respectively. 


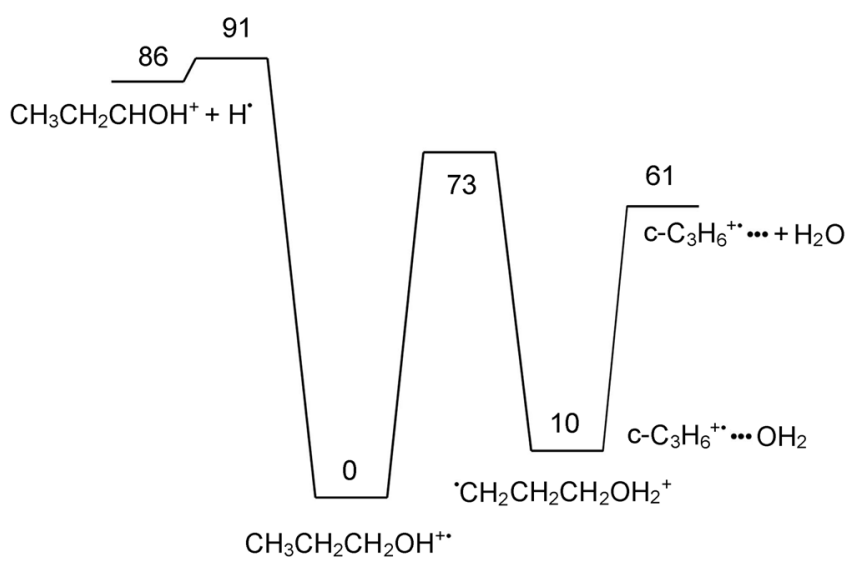

Figure 2. Schematic potential energy surface for the dissociation of $n$-propanol cation. The numbers are relative energies in $\mathrm{kJ} \mathrm{mol}^{-1}$ calculated at the B3LYP/aug-cc-pVQZ//B3LYP/6-31+G(d) level in Ref. 6. Prior to the final loss of water, four intermediates are interconvertible. See text and Ref. 6 for the details.

loss. The MIKE spectrum for the $\mathrm{H}_{2} \mathrm{O}$ loss is shown in Figure 1a. The method to evaluate KERD from a MIKE profile is well established. ${ }^{11}$ The KERD obtained by analyzing the profile in Figure 1a is shown in Figure 1b. The narrow shape of the KERD implies that it is determined by statistical energy distribution between the degrees of freedom of the fragments. Generally, a narrow KERD is an evidence for an exit dissociation channel without a considerable reverse barrier. The PES reported previously ${ }^{6}$ can be approximated as a two-well PES as shown in Figure 2. The intermediate ${ }^{\circ} \mathrm{CH}_{2} \mathrm{CH}_{2} \mathrm{CH}_{2} \mathrm{OH}_{2}{ }^{+}$further isomerizes consecutively to the other conformer and two forms of ion-dipole

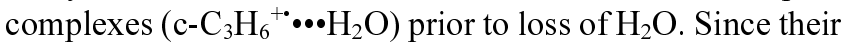
interconversion is predicted to be very fast, their potentials are described as a single well in Figure 2 for convenience. The present KERD agrees qualitatively with the reported PES, in which the final exit channel $\mathrm{c}-\mathrm{C}_{3} \mathrm{H}_{6}{ }^{+} \cdot \bullet \cdot \mathrm{H}_{2} \mathrm{O} \rightarrow$ c- $\mathrm{C}_{3} \mathrm{H}_{6}{ }^{+\bullet}+\mathrm{H}_{2} \mathrm{O}$ does not have a reverse barrier.

It is well known that a KERD in dissociation of polyatomic ions can be well predicted by the statistical PST assuming an orbiting transition state (OTS) when the reverse barrier is negligible. To evaluate the KERD in the $\mathrm{H}_{2} \mathrm{O}$ loss theoretically the following formalism was used: ${ }^{10,11}$

$n(T ; J, E) \propto \int_{E_{\mathrm{R}, \mathrm{m}}}^{E-E_{0}-T} \rho\left(E-E_{0}-T-E_{R}\right) P\left(T, J, E_{\mathrm{R}}\right) \mathrm{d} E_{\mathrm{R}}$,

where $n(T ; J, E)$ is the distribution of $\operatorname{KER}(T)$ at the angular momentum $J$ and the internal energy $E, \rho$ and $P$ are the product vibrational and angular momentum state densities, respectively, $E_{\mathrm{R}}$ is the product rotational energy, $E_{\mathrm{R}, \mathrm{m}}$ is its minimum, and $E_{0}$ is the reaction critical energy. The rootmean-square average $J(44)$ evaluated at the ion source temperature $\left(150{ }^{\circ} \mathrm{C}\right)$ was used. It is assumed that the OTS is located at the maximum of the effective potential determined by each orbital angular momentum and the Langevin potential. ${ }^{10}$ The calculation method was described in detail elsewhere. $^{11}$

To calculate the KERD, we should know the internal energy of $n$-propanol ion undergoing metastable dissociation. The observed metastable dissociation occurred in the field free region between the magnetic and electric sectors. The flight time $(\tau)$ of the molecular ion from the ion source to the intermediate focal point located in the field free region is $\sim 21 \mu \mathrm{s}$, which can be considered as the average lifetime of the dissociating metastable molecular ions. Then, the rate constant for the metastable dissociation is approximated by $\ln 2 / \tau, \sim 3.3 \times 10^{4} \mathrm{~s}^{-1}$. In our previous study, ${ }^{6}$ the rate-energy dependence for the dissociation of $n$-propanol ion was reported theoretically based on the obtained PES. According to the dependence, the internal energy of the molecular ion undergoing metastable dissociation corresponds to $90 \mathrm{~kJ}$ $\mathrm{mol}^{-1}$ at the rate constant $3.3 \times 10^{4} \mathrm{~s}^{-1}$, which can be taken as the average internal energy. Then, the available energy $(E-$ $E_{0}$ ) for the $\mathrm{H}_{2} \mathrm{O}$ loss is $29 \mathrm{~kJ} \mathrm{~mol}^{-1}$ considering the relative energy of $\mathrm{c}_{2} \mathrm{C}_{3} \mathrm{H}_{6}{ }^{+\bullet}+\mathrm{H}_{2} \mathrm{O}\left(61 \mathrm{~kJ} \mathrm{~mol}^{-1}\right.$, see Figure 2). It agrees with the maximum experimental KER (see Figure 1a). Using the estimated internal energy, the theoretical KERD was calculated. The molecular parameters used in the calculation are listed in Table 1. The calculated KERD agrees excellently with the experimental one as shown in Figure $1 \mathrm{~b}$. This indicates that the KERD is determined statistically at the OTS located in the final exit channel c- $\mathrm{C}_{3} \mathrm{H}_{6}{ }^{+} \cdot \bullet \cdot \mathrm{H}_{2} \mathrm{O} \rightarrow \mathrm{c}-\mathrm{C}_{3} \mathrm{H}_{6}{ }^{+\bullet}+\mathrm{H}_{2} \mathrm{O}$ and the energetics reported previously are acceptable. To investigate sensitivity of the KERD on the internal energy, the KERDs were calculated at the available energies at 24 and $34 \mathrm{~kJ} \mathrm{~mol}^{-1}$. The KERDs deviate somewhat from the experimental one, especially at the low KER region (see Figure 1b). Considering typical experimental errors in measurement of KERDs (less than $\pm 10 \%$ probability), we suggest that the accuracy of the present estimation of internal energy by fitting the KERD is within $\pm 5 \mathrm{~kJ} \mathrm{~mol}^{-1}$.

In conclusion, the present and previous results show that the KERD in the $\mathrm{H}_{2} \mathrm{O}$ loss from $n$-propanol cation is determined at the final exit channel c- $\mathrm{C}_{3} \mathrm{H}_{6}{ }^{+} \cdot \bullet \cdot \mathrm{H}_{2} \mathrm{O} \rightarrow \mathrm{c}-\mathrm{C}_{3} \mathrm{H}_{6}{ }^{+\bullet}+$ $\mathrm{H}_{2} \mathrm{O}$, while the rate of the $\mathrm{H}_{2} \mathrm{O}$ loss is determined at the first isomerization $\mathrm{CH}_{3} \mathrm{CH}_{2} \mathrm{CH}_{2} \mathrm{OH}^{+\cdot} \rightarrow{ }^{\circ} \mathrm{CH}_{2} \mathrm{CH}_{2} \mathrm{CH}_{2} \mathrm{OH}_{2}^{+}$ because the followed reactions occur much faster. The

Table 1. Molecular parameters used in the PST KERD calculations

Vibrational frequency $\left(\mathrm{cm}^{-1}\right)$

c- $\mathrm{C}_{3} \mathrm{H}_{6}{ }^{+\bullet a} 453,502,536,673,865,886,994,1013,1063,1173$, $1186,1234,1482,1483,1537,3101,3168,3179,3188$, 3288,3294

$\mathrm{H}_{2} \mathrm{O}^{b} \quad 1595,3652,3756$

\begin{tabular}{|c|c|c|c|}
\hline \multirow[b]{2}{*}{$\mathrm{c}-\mathrm{C}_{3} \mathrm{H}_{6}^{+\bullet}$} & \multicolumn{3}{|c|}{ Rotational frequency $\left(\mathrm{cm}^{-1}\right)^{-}$} \\
\hline & 0.77 & 0.50 & 0.38 \\
\hline \multirow[t]{2}{*}{$\mathrm{H}_{2} \mathrm{O}$} & 27.8 & 14.1 & 9.31 \\
\hline & \multicolumn{3}{|c|}{ Polarizability $\left(10^{-24} \mathrm{~cm}^{3}\right)^{c}$} \\
\hline
\end{tabular}

$\mathrm{H}_{2} \mathrm{O} \quad 1.45$

${ }^{a}$ DFT calculation at the B3LYP/6-31+G(d) level (ref. 6). ${ }^{b}$ Ref. $13 .{ }^{c}$ Ref. 14. 
excellent agreement between the experimental and calculated KERDs supports the reliability of the reported PES and the previous prediction of the dissociation rate constant by RRKM modeling. This work shows that investigation of KER is very useful in understanding of nature of exit channels in unimolecular ionic dissociations.

Acknowledgement. The author thanks Professor Myung Soo Kim of Seoul National University for the use of the mass spectrometer.

\section{References}

1. Refaey, K. M. A.; Chupka, W. A. J. Chem. Phys. 1968, 48, 5205.

2. Shao, J. D.; Baer, T.; Lewis, D. K. J. Phys. Chem. 1988, 92, 5123.

3. Bowen, R. D.; Mandeville, S. J.; Trikoupis, M. A.; Terlouw, J. K. Chem. Commun. 1999, 2111.
4. Booze, J. A.; Baer, T. J. Phys. Chem. 1992, 96, 5710.

5. Bouchoux, G.; Choret, N. Int. J. Mass Spectrom. 2000, 201, 161

6. Choe, J. C. Int. J. Mass Spectrom. 2005, 245, 53.

7. Baer, T.; Hase, W. L. Unimolecular Reaction Dynamics: Theory and Experiments; Oxford, New York, 1996.

8. Cooks, R. G.; Beynon, J. H.; Caprioli, R. M.; Lester, G. R. Metastable Ions; Elsevier: Amsterdam, 1973.

9. Light, J. C. J. Chem. Phys. 1964, 40, 3221.

10. Chesnavich, W. J.; Bowers, M. T. J. Am. Chem. Soc. 1976, 98, 8301; J. Chem. Phys. 1977, 66, 2306.

11. Choe, J. C.; Kim, B. J.; Kim, M. S. Bull. Korean Chem. Soc. 1989, 10, 167.

12. Yeh, I. C.; Kim, M. S. Rapid Commun. Mass Spectrom. 1992, 6, $115 ; 293$.

13. Herzberg, G. Molecular Spectra and Molecular Structure II. Infrared and Raman Spectra of Polyatomic Molecules; Van Nostrand Reinhold: New York, 1945; p 281.

14. Handbook of Chemistry and Physics, $76^{\text {th }}$ ed.; Lide, D. R., Ed.; CRC: Cleveland, 1995. 